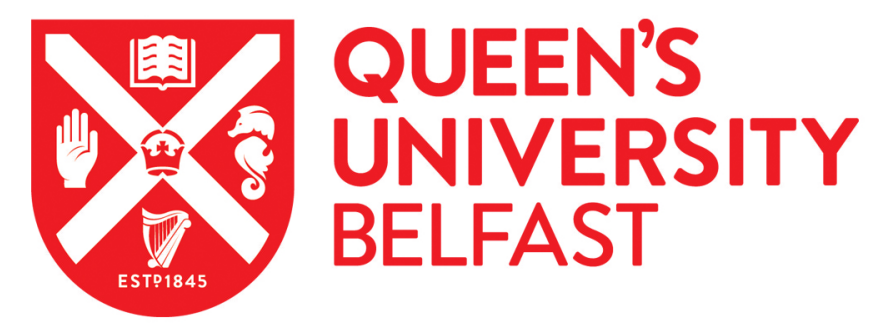

\title{
Uses of Agent-Based Modeling for Health Communication: the TELL ME Case Study
}

\author{
Barbrook-Johnson, P., Badham, J., \& Gilbert, N. (2016). Uses of Agent-Based Modeling for Health \\ Communication: the TELL ME Case Study. Health Communication, 1-6. \\ https://doi.org/10.1080/10410236.2016.1196414
}

\section{Published in:}

Health Communication

\section{Document Version:}

Peer reviewed version

\section{Queen's University Belfast - Research Portal:}

Link to publication record in Queen's University Belfast Research Portal

\section{Publisher rights}

(C) 2016 Taylor \& Francis

This is an Accepted Manuscript of an article published by Taylor \& Francis in Health Communication on 19 Jul 2016, available online: http://www.tandfonline.com/doi/full/10.1080/10410236.2016.1196414

\section{General rights}

Copyright for the publications made accessible via the Queen's University Belfast Research Portal is retained by the author(s) and / or other copyright owners and it is a condition of accessing these publications that users recognise and abide by the legal requirements associated with these rights.

\section{Take down policy}

The Research Portal is Queen's institutional repository that provides access to Queen's research output. Every effort has been made to ensure that content in the Research Portal does not infringe any person's rights, or applicable UK laws. If you discover content in the Research Portal that you believe breaches copyright or violates any law, please contact openaccess@qub.ac.uk. 


\title{
USES OF AGENT-BASED MODELING
}

\section{Uses of agent-based modeling for health communication: The TELL ME case study}

\author{
Peter Barbrook-Johnson \\ Jennifer Badham \\ Nigel Gilbert
}

Centre for Research in Social Simulation, University of Surrey, UK

\begin{abstract}
Author Note
Correspondence concerning this article should be addressed to Peter Barbrook-Johnson, Centre for Research in Social Simulation, University of Surrey, GU2 7XH, UK. Email: p.barbrook-johnson@surrey.ac.uk
\end{abstract}




\title{
USES OF AGENT-BASED MODELING
}

\begin{abstract}
Government communication is an important management tool during a public health crisis, but understanding its impact is difficult. Strategies may be adjusted in reaction to developments on the ground and it is challenging to evaluate the impact of communication separately from other crisis management activities. Agent-based modeling is a well-established research tool in social science to respond to similar challenges. However, there have been few such models in public health. We use the example of the TELL ME agent-based model to consider ways in which a non-predictive policy model can assist policy makers. This model concerns individuals' protective behaviors in response to an epidemic, and the communication that influences such behavior. Drawing on findings from stakeholder workshops and the results of the model itself, we suggest such a model can be useful: (i) as a teaching tool, (ii) to test theory, and (iii) to inform data collection. We also plot a path for development of similar models that could assist with communication planning for epidemics.
\end{abstract}

Keywords: influenza, epidemics, agent-based modeling, policy modeling 


\section{USES OF AGENT-BASED MODELING}

\section{Uses of agent-based modeling for health communication: The TELL ME case study}

Communication to the public on how to minimize the risk of infection is the only tool, beyond vaccination, available to public health agencies during an influenza epidemic (Crosier, McVey, \& French, 2014; Lin, Savoia, Agboola, \& Viswanath, 2014). As such, it is vitally important that planners develop effective evidence-based communication strategies. However, this can be challenging, with the unpredictable timing and nature of new epidemics, and lack of rigorous empirical research into the effects of communications plans (Lin et al., 2014; Savoia, Lin, \& Viswanath, 2013).

This paper introduces agent-based modeling and explores how agent-based models (ABMs) can be of value in responding to this combination of challenges faced by public health communicators. Agent-based modeling is 'a computational method that enables a researcher to create, analyze, and experiment with models composed of agents that interact within an environment' (Abdou, Hamill, \& Gilbert, 2012, p. 141). Over the last forty years, agent-based modeling has become an increasingly popular approach for exploring ideas about the social world (Axelrod, 1997; Epstein \& Axtell, 1995; Gilbert \& Troitzsch, 2005). While use is in its infancy in public health, there have already been ABMs developed in areas as diverse as epidemiology, illicit drugs and physical activity (Dray et al., 2012; Liu et al., 2015; Yang et al, 2011).

ABMs are computer programs that encode important actors (the 'agents'), their behavior, their interaction with each other, interaction with their environment, and any policy interventions. The design of ABMs is typically underpinned by theoretical frameworks and empirical findings from surveys and questionnaires. Once built, the models can be 'run' many 


\section{USES OF AGENT-BASED MODELING}

times with different starting parameters, thus allowing experimentation and analysis with the simulation model.

In the context of health communication during an epidemic, this approach was used in the TELL ME project to allow simulated people to respond to communication messages according to their own attitudes, epidemic proximity and other relevant considerations. This paper examines how such a model can be useful for policy making, despite limitations in data and knowledge of behavior that make it impossible to generate point predictions.

This paper is structured as follows. The next section will introduce the TELL ME model. The Methods section then describes the workshops and other activities that we draw from to provide evidence of how the model could be useful to health communication stakeholders. The

Results section presents the key findings, based around three uses of the model: (i) as a teaching tool, (ii) as a formal thought experiment to test theory, and (iii) to inform data collection. The conclusion generalizes from the specific example of the TELL ME model, which is a prototype applied to one specific policy area, to discuss one way forward for the use of non-predictive ABMs in health communication planning.

\section{The TELL ME ABM}

\section{Overview}

The European funded TELL ME project focused on health communication associated with influenza epidemics. One output was a prototype ABM, intended to be used by health communicators to understand the potential effects of different communication plans under various influenza epidemic scenarios.

The basic structure of the model is determined by its purpose: to compare the potential effects of different communication plans on protective personal behavior and hence on the 


\section{USES OF AGENT-BASED MODELING}

spread of an influenza epidemic. This requires two linked models: a behavior model that simulates the way in which people respond to communication and make decisions about whether to vaccinate or adopt other protective behavior, and an epidemic model that simulates the spread of influenza. The key model entities are: (i) messages, which together implement the communication plans; (ii) individuals, who receive communication and make decisions about whether to adopt protective behavior; and (iii) regions, which hold information about the local epidemic state. The major flow of influence is the effect that communication has on attitude and hence behavior, which affects epidemic transmission and hence incidence. Incidence contributes to perceived risk, which influences behavior and establishes a feedback relationship (see Badham \& Gilbert, 2015 for the detailed specifification).

The TELL ME model was developed using the open source programming environment NetLogo (Wilensky, 1999). NetLogo allows users to easily change parameters in the model and run experiments. The model can be downloaded at http://www.tellmeproject.eu/content/socialsimulation-model.

\section{Individual Protective Behavior}

The simulated individuals in the model decide whether to adopt (or drop) protective behavior based on whether the weighted average of attitude, subjective norms, and perceived threat exceeds (or falls below) a threshold value. These influences are derived from (i) The Theory of Planned Behavior (Ajzen, 1991), which is the dominant general purpose behavior model in the applied psychological research literature; and (ii) The Health Belief Model (Rosenstock, 1974) and (iii) the Protection Motivation Theory (Maddux \& Rogers, 1983), which are particularly popular in the health behavior literature. Two types of behavior are separately 


\section{USES OF AGENT-BASED MODELING}

modeled, each with their own weights and thresholds: vaccination, and 'other protective' (everything else, including hygiene and social distancing).

Attitude is modeled as a value between 0 and 1 that represents an individual's willingness to adopt the behavior in the right circumstances, including such aspects as perception of effectiveness and difficulty. Norms are operationalized as the proportion of the nearby individuals that have adopted the behavior, representing how a person believes other people expect them to behave.

Threat represents both perceived susceptibility and the consequences of becoming infected (severity and an emotional fear element). Adapting the method of Durham \& Casman (2012), susceptibility is modeled with a discounted cumulative incidence time series, but with only nearby cases counted. Threat will generally be higher for those simulated individuals who are close to the new cases than for those further away, and will decrease as the epidemic passes.

\section{The Effect of Communication}

Communication plans are provided to the model as a set of 'messages'. Each message is constructed from pre-determined choices that control timing (e.g., every 10 days), targeting (media channel and population group) and content. Simulated individuals respond to received messages according to the message content, which can take the values of: promoting benefits; providing epidemic status information, emphasizing norms, and recommending adoption. The first two message content types lead to a permanent change in a person's attitude and trust values respectively. The other two content types temporarily increase the perception of norms and threat respectively. The communication therefore influences the decision to adopt or drop protective behavior by changing the factors that contribute to the decision. 


\section{USES OF AGENT-BASED MODELING}

This is necessarily a very simplified implementation of communication. While the impact of communication depends on many contextual factors that influence how a message is encoded by the sender and decoded by the receiver (Hall, 1980), such a nuanced approach is neither feasible nor desirable for a prototype ABM.

\section{Epidemiology}

Regions (a grid of 'patches' that make up the model environment) manage the epidemic modeling. A standard SEIR model of influenza transmission is used (Diekmann \& Heesterbeek, 2000): People start in the susceptible (S) state, become exposed (E) but not yet infectious, then become infectious (I) and are eventually removed from calculations (R) because they recover and become immune. At each simulation time step, equations are used to update the proportion of the population in each state.

The greater the proportion of the simulated individuals who are protecting themselves, the slower the epidemic spreads. The progress of the epidemic in turn influences behavior through the impact on perception of threat. Thus, all the elements of the model are connected and influence each other.

\section{Methods}

To bring together a coherent explanation of how a non-predictive policy ABM can be useful to health communication stakeholders, two approaches are combined. We will present stakeholders' views of the model and its potential, expressed in four workshops held at various stages during the model's development. We will also explore the model's output for specific 'training' type scenarios to demonstrate particular uses.

Four stakeholder workshops were held during the TELL ME model development to provide input to the model design and evaluate the draft prototype. The workshops had different 


\section{USES OF AGENT-BASED MODELING}

participants and content to reflect their specific aims and objectives. However, all workshops included a discussion of stakeholders' opinion of the model (or model design) and potential uses.

Participants' input was in the form of comments made during presentations, conversations during discussion sessions and, in the case of the first workshop, summaries generated by each small group about specific design issues. As these workshops were meetings to discuss the model rather than formal qualitative studies, they were not recorded. However, a dedicated note-taker was present at each workshop to record as much detail as possible about the discussion. The notes were in the form of shortened or paraphrased versions of the discussion during the workshops. Shortly after each workshop, the notes were used to write a detailed summary of the discussion, and were checked by the other researcher present at the workshops. The notes were analyzed using a basic thematic analysis, which focused on participant's responses and comments regarding the potential use and usefulness of the model.

In addition, the fourth workshop included a questionnaire to supplement the discussion. The questionnaire contained a combination of multiple choice and open-ended questions. These focused on (i) validating the macro-behavior of the model, and asking for open-text explanations of participants' views; and (ii) seeking feedback on the model's usability.

\section{Workshops 1 and 2 (UK1 and UK2)}

The two United Kingdom workshops were held in London at a nationally recognized health institution on 31 July 2013 and 6 October 2014. The first workshop had ten participants from government public health, academic and health charity organizations, as well as the model development team. Their roles and expertise covered health communication, behavior, epidemiology and crisis management. Four participants (or their nominees) attended the second workshop. 


\section{USES OF AGENT-BASED MODELING}

The focus of UK1 was the model design, and the factors that needed to be included in the simulation decision-making and how these could be operationalized. UK2 presented the draft model and showed how that design advice had been incorporated. This latter workshop was part of the model validation, to obtain stakeholder views on the implemented rules and resulting outputs of the model, and gain insight into how the participants viewed the potential for the model to be used by planners.

\section{Workshops 3 and 4 (USA and EU validation)}

The remaining workshops were part of the formal validation process for the model, presenting it to planners and other health professionals for feedback. The United States workshop was held in Washington DC on 8 October 2014 with four health disaster managers from government and non-government organizations. The European workshop was held in Budapest, Hungary on 21 November 2014 in tandem with a meeting of a European level general practitioner organization. It was run twice during the day with fifteen participants in each group. The participants were all general practitioners from within Europe who had various additional roles such as working with public health agencies. The discussion was supplemented with a questionnaire, with seventeen completed questionnaires returned.

The workshops in total had forty-eight participants. This is a reasonable number given the aims of this paper, and the difficulty in making contact with large numbers of senior public health professionals.

\section{Results}

There were three policy uses that emerged from model development, discussion of outputs and stakeholder workshops. These were: (i) as a teaching tool, (ii) for identifying weaknesses in theory, and (iii) for informing data collection. 


\section{USES OF AGENT-BASED MODELING}

\section{Teaching tool}

The model can be run using unrealistic 'training' scenarios. Such scenarios were used in the workshops to demonstrate that the model implements the design as intended, and to help participants become familiar with the model and understand its various components and influences.

Figure 1 presents behavior adoption and epidemic progress for one set of related scenarios: (i) the baseline epidemic, where there is no communication and any protective behavior is ineffective, (ii) the same epidemic with a simple communication plan (two messages, promoting other protective behaviors via attitude at day 20 and promoting vaccination via norms at day 40), and (iii) the same epidemic and communications plan, but with protective behavior reducing transmission (by $60 \%$ for vaccination and $25 \%$ for other protective behavior). The effect of the communication campaign can be clearly seen in the comparison between the baseline and communication scenarios in the top two panels, with a sudden temporary increase in adoption at the relevant day. If that behavior is effective however (influence scenario), the epidemic is less threatening and protective behavior is actually lower than occurs in the baseline scenario.

\section{[Insert Figure 1]}

This interaction of personal and epidemic behavior highlights the difficulty in estimating the effects of proposed actions in a complex system, and the important role for models in understanding such systems. By comparing the three scenarios we can begin to understand the feedbacks and nuances of the planning process. Comparing scenarios immediately makes clear the counter-intuitive feedback between communication, efficacy of protective behavior and the adoption. When communication is present and behavior is effective, as people adopt other 


\section{USES OF AGENT-BASED MODELING}

protective behaviors there is a reduction in the epidemic's spread, which mean that fewer people actually end up adopting behavior early on. The weaker epidemic (shown in the infections graph), and thus reduced influence of perceived threat and social norms mean there is less pressure to adopt, despite the increased efficacy of communication.

While these scenarios were presented to stakeholders to demonstrate model features, participants at the second UK workshop saw a lot of value more generally for students of public health and communication. It was suggested the model could be used as a teaching tool to aid training of students and junior staff by illustrating the complexity (in the formal sense of a complex system) of the planning process. The model can be used to run many combinations of scenarios, with varying types of differences. This allows users to search for tipping points in the

model, seek out counter-intuitive results, and most importantly, create hypotheses and test them. When the model does not conform to users' beliefs, they can go back to the model rules and assumptions, and seek to understand what has created the difference. This process of exploring the model results through a range of scenarios will have value for those wishing to understand the complexity of the system as a whole and allow careful consideration about cause and effect, and the impact of different influences in the system.

\section{Testing theory: identifying partialness or weakness}

During each of the workshops, participants found the model credible in its representation of the way epidemics spread in the model and the way communication impacted on behavior, asserting that the model produced qualitatively realistic results. For example, $65 \%$ of EU workshop questionnaire respondents agreed the model results were realistic, with the remaining $30 \%$ agreeing they were partially realistic (and 6\% not responding). 


\section{USES OF AGENT-BASED MODELING}

However, that confidence was misplaced; the model was unable to reproduce empirical results. A study of protective behavior during the 2009 influenza epidemic in Hong Kong (Cowling et al., 2010) provided real world data about adoption over the course of the epidemic, reporting that behavior peaked 55 days prior to the peak of the epidemic. In contrast, the model could only produce results with behavior peaking after the epidemic.

One plausible explanation of this mismatch may be that people were reacting to potential threat and had already adopted (and in some cases dropped) before the real threat emerged. Relevant Hong Kong headlines peaked in the week ending 2 May 2009 (Google Trends, n.d.), even though the height of the epidemic occurred in late September (Cowling et al., 2010). The process of implementing theories about the real world in a simulation has allowed us to highlight potential problems (in this case, timing) and propose additional theoretical aspects to be included (effect of headlines). That is, the simulation provides a rigorous alternative to a thought experiment.

\section{Informing data collection}

The rigor of the model development process also highlighted gaps in data. During the workshops, availability of data was raised on several occasions, suggesting that stakeholders are aware of limitations in data and the potential benefit of additional collection.

Longitudinal data (Windrum, Fagiolo, \& Moneta, 2007), collected both before and after communication strategies have been used in an epidemic, is needed. These data should measure behavior but also the factors that contribute to that behavior (such as attitude). Post-hoc evaluations that ask whether a person engaged in protective behavior and whether they remember receiving the communication provide no information about how they would have 


\section{USES OF AGENT-BASED MODELING}

behaved without the communication nor the process by which the communication changed the behavior.

In addition, the relative contribution of different influences on the decision (i.e., social norms, perceived threat, communication) are difficult values to elicit in interviews, surveys or experiments. However, some aspects are more accessible, such as the strength of attitudes about protective behavior and changes in attitude arising from different types of communication. These data would provide useful information for both evaluation of communication and future model building.

\section{Conclusion}

This paper has described an agent-based model used in the TELL ME project to assess the suitability of this modeling technique for communication planning during epidemics. While agent-based modeling is not yet viable as a predictive and evaluation tool in this setting, the paper has demonstrated several ways in which the method can already be useful to policy makers and students of public health and health communication.

Drawing on experiences at stakeholder workshops and results from the model itself, it was suggested that the model has value as: (i) a teaching tool to aid learners in grasping the complexity of the effects of communication during influenza epidemics; (ii) a test of the adequacy of theoretical understanding of behavior; and (iii) a tool to inform future data collection, particularly concerning behavior over time and the impact of health communication. It also provides an illustration of how a non-predictive policy model can be useful in other policy areas that are characterized by many individual actors interacting with each other and their environment. 


\section{USES OF AGENT-BASED MODELING}

It is important to note that the TELL ME ABM is a prototype. It will need significant further development before it can claim to be a mature model with value as a predictive tool for policy makers. So what is needed for this, or any other ABM, to reach this mature state?

First comes the question of prediction. Additional data on past epidemics and individual behavior would allow for improved parameterization and stronger validation of the model, which would allow for more trustworthy forecasting. However, point prediction is unlikely ever to be within an ABM's capabilities, because the complexity and noise inherent in the policy problem is placed inside the model. Instead the model could be used to suggest plausible outcomes.

Whilst more data is undeniably important, its collection must go alongside continued development of theory and models of decision-making. Improved theories of individual decisionmaking and interaction will give models a stronger footing on which to base their assumptions. As data and theory improve, so too will the (prototype) models developed using that support. This could then lead to improved data collection and theory building, creating a positive feedback between the three.

\section{Acknowledgements}

We wish to thank the TELL ME project partners and workshop participants for their input into this work.

\section{Funding}

This research has received funding from the European Research Council under the European Union's Seventh Framework Programme (FP/2007-2013), Grant Agreement number 278723. The full project title is TELL ME: Transparent communication in Epidemics: Learning Lessons from experience, delivering effective Messages, providing Evidence, with details at http://tellmeproject.eu/. 


\section{USES OF AGENT-BASED MODELING}

\section{References}

Abdou, M., Hamill, L., \& Gilbert, N. (2012). Designing and building an agent-based model. In
A. J. Heppenstall, A. T. Crooks, L. M. See, \& M. Batty (Eds.), Agent-based models of geographical systems (pp. 141-165). Dordrecht: Springer.

Ajzen, I. (1991). The theory of planned behavior. Organizational Behavior and Human Decision Processes, 50, 179-211. doi:10.1016/0749-5978(91)90020-T

Axelrod, R. (1997). Advancing the art of simulation in the social sciences. In R. Conte, R. Hegselmann, \& P. Terna (Eds.), Simulating social phenomena (Vol. 3, pp. 21-40). Berlin: Springer-Verlag. doi:10.1007/978-3-662-03366-1_2

Badham, J. M., \& Gilbert, N. (2015). TELL ME design: Protective behaviour during an epidemic. Centre for Research in Social Simulation Working Paper, University of Surrey. Retrieved from http://cress.soc.surrey.ac.uk/web/publications/working-papers/tell-medesign-protective-behaviour-during-epidemic

Cowling, B. J., Ng, D. M. W., Ip, D. K. M., Liao, Q., Lam, W. W. T., Wu, J. T., ... Fielding, R. (2010). Community psychological and behavioral responses through the first wave of the 2009 influenza $\mathrm{A}(\mathrm{H} 1 \mathrm{N1})$ pandemic in Hong Kong. The Journal of Infectious Diseases, 202, 867-876. doi:10.1086/655811

Crosier, A., McVey, D., \& French, J. (2014). "By failing to prepare you are preparing to fail”: Lessons from the 2009 H1N1 "swine flu" pandemic. The European Journal of Public Health, 25, 135-139. doi:10.1093/eurpub/cku131 


\section{USES OF AGENT-BASED MODELING}

Diekmann, O., \& Heesterbeek, J. (2000). Mathematical epidemiology of infectious diseases. Chichester: Wiley.

Dray, A., Perez, P., Moore, D., Dietze, P., Bammer, G., Jenkinson, R., ... Maher, L. (2012). Are drug detection dogs and mass-media campaigns likely to be effective policy responses to psychostimulant use and related harm? Results from an agent-based simulation model. The International Journal on Drug Policy, 23, 148-153. doi:10.1016/j.drugpo.2011.05.018

Durham, D. P., \& Casman, E. A. (2012). Incorporating individual health-protective decisions into disease transmission models: a mathematical framework. Journal of The Royal Society Interface, 9, 562-570. doi:10.1098/rsif.2011.0325

Epstein, J. M., \& Axtell, R. L. (1995). Growing artificial societies: Social science from the bottom up. Washington DC: Brookings Institution.

Gilbert, N., \& Troitzsch, K. G. (2005). Simulation for the social scientist (2nd ed.). Glasgow: Open University Press.

Google Trends. (n.d.). [Headlines with H1N1 or flu, Hong Kong 2009]. Retrieved from http://www.google.co.uk/trends/

Hall, S. (1980). Encoding/decoding. In S. Hall, D. Hobson, A. Lowe, \& P. Willis (Eds.), Culture, media, language: Working papers in cultural studies 1972-79 (pp. 166-176). London: Hutchison. 


\section{USES OF AGENT-BASED MODELING}

Lin, L., Savoia, E., Agboola, F., \& Viswanath, K. (2014). What have we learned about communication inequalities during the $\mathrm{H} 1 \mathrm{~N} 1$ pandemic : a systematic review of the literature. BMC Public Health, 14, 484. doi:10.1186/1471-2458-14-484

Liu, F., Enanoria, W. T. A., Zipprich, J., Blumberg, S., Harriman, K., Ackley, S. F., ... Porco, T. C. (2015). The role of vaccination coverage, individual behaviors, and the public health response in the control of measles epidemics: an agent-based simulation for California. BMC Public Health, 15, 447. doi:10.1186/s12889-015-1766-6

Maddux, J. E., \& Rogers, R. W. (1983). Protection motivation and self-efficacy: A revised theory of fear appeals and attitude change. Journal of Experimental Social Psychology, 19, 469-479. doi:10.1016/0022-1031(83)90023-9

Rosenstock, I. M. (1974). The health belief model and preventive health behavior. Health Education \& Behavior, 2, 354-386. doi:10.1177/109019817400200405

Savoia, E., Lin, L., \& Viswanath, K. (2013). Communications in public health emergency preparedness: A systematic review of the literature. Biosecurity and Bioterrorism: Biodefense Strategy, Practice, and Science, 11, 170-184. doi:10.1089/bsp.2013.0038

Wilensky, U. (1999). NetLogo [computer software]. Evanston, IL: Center for Connected Learning and Computer-Based Modeling, Northwestern University.

Windrum, P., Fagiolo, G., \& Moneta, A. (2007). Empirical validation of agent-based models: Alternatives and prospects. Journal of Artificial Societies and Social Simulation, 10, 8. 


\section{USES OF AGENT-BASED MODELING}

Yang, Y., Diez Roux, A. V., Auchincloss, A. H., Rodriguez, D. A., \& Brown, D. G. (2011). A spatial agent-based model for the simulation of adults' daily walking within a city.

American Journal of Preventive Medicine, 40, 353-361. doi:10.1016/j.amepre.2010.11.017 


\section{USES OF AGENT-BASED MODELING}
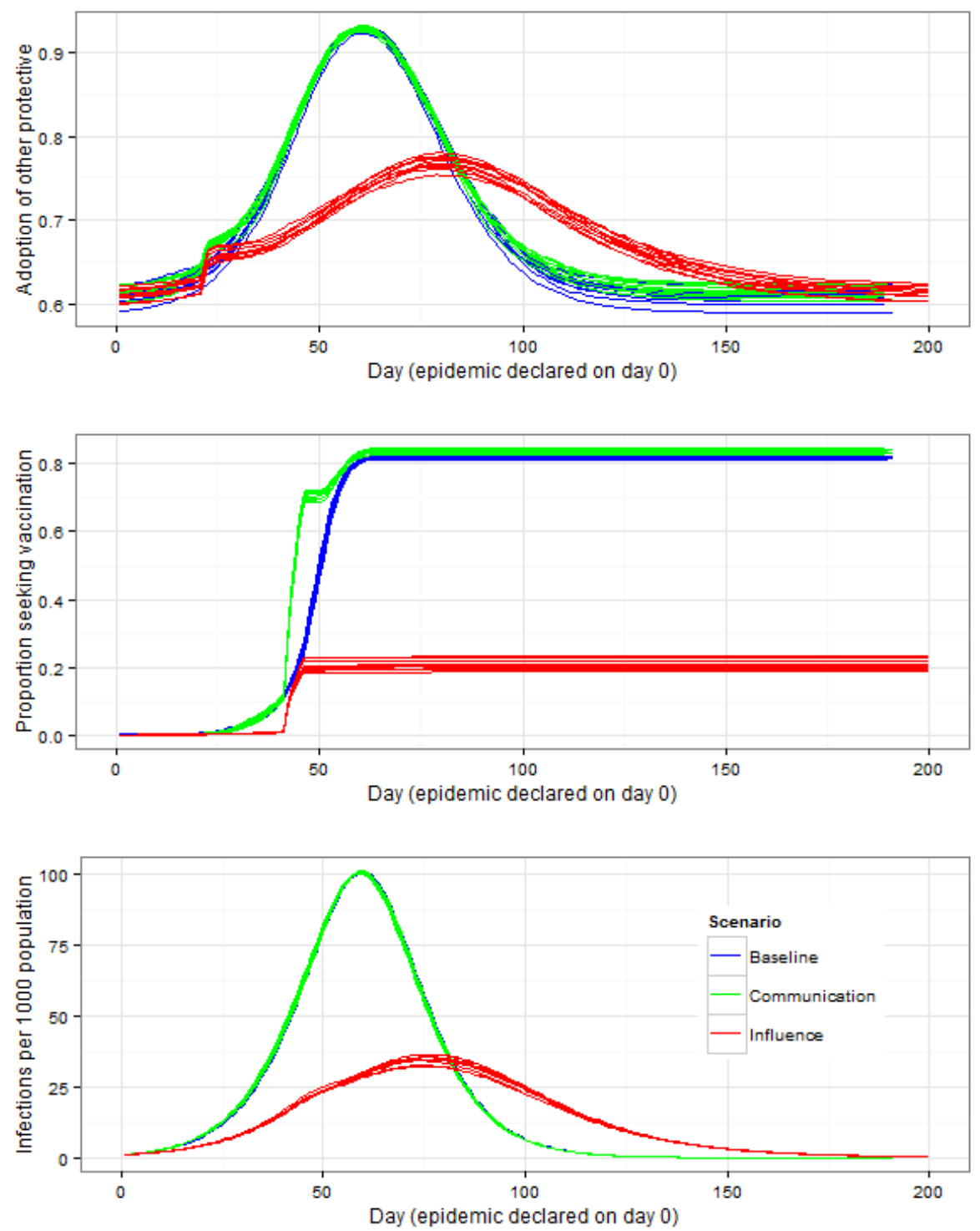

Figure 1: (Top) Proportion adopting protective behavior, (Middle) Proportion seeking vaccination, and (Bottom) Number of new infections under three scenarios. The baseline assumes no communication and that protective behavior is ineffective. It thus displays the 'natural' progress of the epidemic in the absence of any management. In the communication scenario, there is a message promoting non-vaccination behavior at day 20 and one promoting vaccination at day 40 . The model is set so that a message has a significant effect, which can be seen in the top two panels. However, the behavior is ineffective so the epidemic curve is 


\section{USES OF AGENT-BASED MODELING}

identical. In the influence scenario, the same epidemic and communication inputs are used, but the behavior is assumed efficacious, which reduces the impact of the epidemic. 